\title{
Sustainable and Responsible ICT Innovation in Healthcare: A Long View and Continuous Ethical Watch Required
}

\author{
Tony Cornford and Valentina Lichtner \\ Information Systems and Innovation Group, \\ London School of Economics and Political Sciences, London, United Kingdom \\ $\{$ t. cornford, v.lichtner\}@lse.ac.uk
}

\begin{abstract}
Healthcare is of central importance to all communities and generally has a high political profile. Access and availability of care, rising costs, and emerging new relationships between experts (doctors and nurses) and users (patients, citizens) pose new challenges. ICT-based innovation is often proposed as a solution, accompanied by optimistic accounts of its transformative potential, both for the developing world and the developed. These ambitions also implicitly endorse new social agreements and business models. In this respect, as in others, technology is not neutral or simple in the service of modernization; it has its own politics. This paper discusses ICT innovation in healthcare in these terms focused on issues of sustainability and responsibility adapting two economic concepts: redistribution and externalities. The analysis reveals ICT innovation in health care as essentially raising 'trans-scientific' questions - matters of policy and intergenerational ethics rather than narrow science.
\end{abstract}

Keywords: healthcare, ICT, technological innovation, sustainability, ethics, redistribution, externalities.

\section{$1 \quad$ Introduction}

Today's healthcare challenges and their potential technological 'solutions' are well known. They appear as an often-repeated 'mantra' in the opening paragraph of publications on health policy and information technology (e.g. [1]). The basic themes are low-growth and aging western economies facing a future with an increasingly expensive and less affordable healthcare system. Important drivers of the growing burden placed on these systems, and on public health and economic life in general, comes from the complex mixture of an aging population with multiple care and medical needs, and the availability of expensive new treatments. These themes are combined in the rising numbers of people with chronic but increasingly treatable conditions such as diabetes or COPD which are life-style related and require treatments 'for life'. As a consequence, the mission of healthcare is increasingly directed towards assisting people to live well, a matter of prevention and quality of life rather than narrowly medical concerns of diagnosis and treatment, or matters of 'life or death'. 
These pressures are compounded in a globalised world by movement of people across borders, which leads to concern over faster and wider spread of diseases and epidemics (e.g. [2], [3]). London, for example, has now a substantial programme to combat TB [4], a disease that was considered exceptional a generation ago. We also see migration among healthcare professionals, with many developed countries dependent on doctors and nurses recruited away from countries with greater health needs.

Against this background it is perhaps unsurprising that information and communication technologies (ICT), ubiquitous access to networks and data, and the rapid growth of mobile and distributed computing, offers enticing opportunities for reducing costs of service provision, raising effectiveness of interventions and improving access to healthcare [5], [6]. In this paper we discuss some of the consequences of increased reliance on ICT innovations in healthcare systems - the socio-technical consequences across time and space. We thus consider the sustainability of the deepening engagement of healthcare systems with digital technologies and consider the ethical questions posed. In presenting this analysis we develop our argument around the twin themes of redistribution and externalities.

\section{ICT Innovation in Healthcare}

The penetration of healthcare by digital technologies occurs at many levels and in many places. Here we highlight three contemporary and contrasting examples.

Digital Imaging. There has been in the last decade a move from film based x-rays to digital imaging technologies. There is reasonable evidence of immediate clinical benefit arising from networked sharing of this information, credible expectation of cost saving over time, and real environmental benefits from the use of fewer chemicals in film processing [7]. Digital images and scans also are available to become part of an electronic patient record, which can serve clinical decisions making that draws upon more complete patient information.

Telemedicine ('Consultation at a Distance'). Telecommunications and networks can obviate patient travel (e.g. to hospital), and optimize access to and sharing of medical expertise. Telemedicine has found successful implementations in geographically remote regions, improving access to care and expertise, but also in reorganization of emergency services such as stroke care (e.g. [8]) or more generally interlinking primary and secondary care. We may also extend the definition to technologies for assisted living (telecare), with technologies serving to allow people to remain in their homes longer thus avoiding hospitalization costs and improving quality of life. Telecare, in its various forms, has been reported in England to generate potential savings such as " $45 \%$ reduction in mortality rates, $20 \%$ reduction in emergency admissions, $15 \%$ reduction in $\mathrm{A} \& \mathrm{E}$ visits, $14 \%$ reduction in elective admissions, $14 \%$ reduction in bed days, $8 \%$ reduction in tariff costs" [9]. 
Patient Centered Care. Patient accessed and managed health services are now provided digitally. While telemedicine and telecare maintain broadly the traditional service model (doctor - nurse - patient), there are a set of technological innovations applied in healthcare, often delivered on the Internet or by mobile phones, that embody greater patient/citizen participation and ownership of health matters. This can lead to a rebalanced (we might even say more equal) doctor-patient relationship, with greater responsibility taken by patient-citizens and their families for their own health and care, or allowing them to by-pass healthcare professionals and healthcare institutions altogether [10]. Online citizen participation can also be a driver of new public health strategies such as online smoking cessation initiatives, the monitoring of epidemics by crowd-sourcing (see http://healthmap.org) or the use of two-way SMS phone messaging to monitor emergencies [11]. Finally, a new form of participatory health research is emerging, with crowd-sourced health research studies complementing, if not yet replacing, more traditional clinical trials [12].

The three broad examples of contemporary technological innovations sketched above suggest distinct aspects of the move to digitalize. First, the gains that derives from new ways to carry out or extend the range of existing types of task (e.g. x-ray imaging) within an established institutional setting. Second, the redistribution of resources across space so as to reconfigure and improve services and support equality of access, and finally a (potential) systemic change as healthcare takes a turn towards the patient-consumer and is less about a 'do to' or 'do for' model and more 'do with' [13] - even 'do alone'.

The most innovative but also potentially disruptive aspects of ICT in healthcare derive from the inherent characteristics of digital innovations to generate, store and share large amounts of data (sometimes described as 'big data') and connect and serve multiple people in both tight or loose social structures. In all these examples we see digital data being generated and changing or rebalancing the way healthcare is delivered, experienced and how and by who control is exercised. Digital data is drawn upon and influences decisions, at large scale as in healthcare planning, pharmaceutical research or population surveillance, clinically as in a clinical decision support systems (DSS), or less formally as in a patient group based discussion forums.

In this sense digital innovation in healthcare is founded on both technical and social networking - sometimes known as web 2.0 (and hence health 2.0) - and embraces in some mix data aggregation and analysis, user-generated content and new business models (open innovation, social networking and the economy of 'free' [14]).

\section{Sustainability and Responsibility: Redistribution and Externalities}

It is certainly not foolish to believe in the potential of digital technologies for changing the nature of service provision across all economic and administrative sectors. In our own lives we see pertinent examples in business (e.g. travel, music) and in the public realm (e-government, e-petitions). And ICT may well offer entirely new 'solutions' to both the old and the new healthcare and public health problems. 
No technology is, however, politically or ethically neutral [15]. All innovation embodies certain interests and neglects others, and there is a risk that digitally innovated systems may not be, in the long term, sustainable whatever specific improvements in aspects of healthcare they deliver. We should apply to digital development within healthcare the spirit of the United Nations definition for sustainable development "[S] ustainable development is development that meets the needs of the present without compromising the ability of future generations to meet their own needs" ([16], emphasis added).

Developmental interventions in society or the economy have effects on the distribution of income or access to resources both within, and given globalisation, beyond national borders, as well as across time. By distributional effects we mean the "modifications of the holdings of particular persons, collective agents, or groups [...] with respect to a "baseline" [17]. What is redistributed may not be only access to resources but roles, risks, and responsibilities. Barry goes on to suggest that redistribution should be understood relative to some defined set of subjects. In healthcare these groups may be, for instance: types of clinicians (e.g. nurses versus doctors), clinical staff versus other healthcare employees (e.g. administrative staff), clinicians versus patients, or in a more macro dimension, healthcare providers (e.g. hospitals versus community care or self-care). It may also be, indeed should be, seen in terms of citizens and generations (e.g. the old versus the young, or the healthy versus the ill).

Some distributional effects are expected from most policies or initiatives, not just those 'purposively' launched for redistributive goals, such as national welfare policies. All of the types of digital interventions in healthcare introduced above have distributional effects across many domains; on access to care, on labour and workload, on professional roles and autonomy, on who bears risk and takes responsibilities, and on doctor-patient relationships [18-21]. Berg [22] for example speaks of the unpredictable and unknown redistribution of responsibilities in future systems built to support a patient-centric workflow and notes that this would probably, "ensure a conflict-rife implementation process; yet it could be an important part of a more patientoriented care process." [22]

Redistributive effects of ICT use may be expected and desired, others may occur as 'unexpected consequences' [23] or what economists would call externalities. The term 'externalities' refers not simply to effects beyond the intended but to "situations when the effect of production or consumption of goods and services imposes costs or benefits on others which are not reflected in the prices charged for the goods and services being provided" [24]. The concept originates from Pigou [25] who identified that the actions of economic agents can and will influence the utility of others without mechanisms for compensation [26] and were later known as external (dis)economies or externalities [27].

Externalities may be negative - e.g. social costs that counterbalance private benefits - or positive - e.g. social benefits that counterbalance private costs. The motorcar is a well-understood example of externalities of the first kind. The technological invention of the combustion engine brought, in the last century in Western countries, freedom of movement to the masses and contributed to women's emancipation. Yet new problems emerged - from accidents, to traffic jams and air and noise pollution. 
Thus the cost for the individual of driving a car does not take adequately into account society's costs - the externalities. Similarly it can be argued that the unfettered use of insurance markets in healthcare cause externalities in the social cost of the uninsured. When private cars were the luxury of a few, their impact on the environment did not present the sustainability challenges that emerge when it becomes a technology for the masses. An example of positive externalities might be the inoculation of children for diseases such as mumps, measles or chicken pox. This has a private cost and benefit for the child or family, but also strong social benefit in the 'herd immunity' it helps to create.

As in the case of the motorcar, also in healthcare, when a technology reaches a significant scale of implementation, the related negative externalities may have longterm consequences for sustainability. By sustainability we refer to both the capacity of the services (and associated technology) to be sustained economically through time (e.g. [28]) as well as the impact on the sustainability of the wider context (social, economical, and environmental) and hence on the ethical worth.

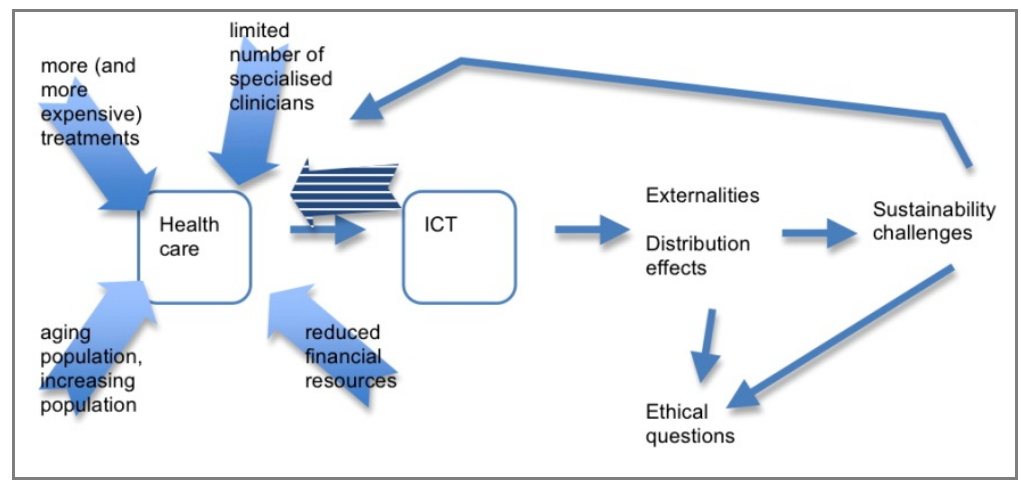

Fig. 1. ICT innovations have a life of their own - what 'can be built' often gets built. But pressures on healthcare lead to ICT innovations intended as a solution to some of these pressure. ICT investments can also constitute one of the pressures on healthcare, e.g. in terms of financial resources. ICT have consequences in terms of externalities and redistributive effects, with ethical implications, and in the long term, sustainability repercussions on other aspects of life (e.g. environment, or social agreements) as well as health itself.

Here we apply this analytical lens of redistribution and externalities to the digitalization of healthcare. We accept that these technologies will deliver individual and current benefits, but also assume that they will present their own distributional effects and externalities - leaving a legacy. Furthermore, the effects of today's technological choice will last through future phases of innovation constraining what is possible (what has been referred to as the 'durability of the present' [29]).

For example, the benefits of telemedicine for patients and carers may be seen in terms of access, convenience and efficiency of clinical services. However, telemedicine will also involve a redistribution of clinical tasks and roles (for example nurses taking over some medical tasks from doctors); a greater social and physical distance 
between doctor and patient (transforming the doctor-patient relationship); a redistribution of associated responsibilities and changes in risks [30]. In telecare the increased efficiency of service provision through a central location - for example a central monitoring station or call centre - potentially produces negative externalities at the periphery as patients lose human contact. In the longer term telecare may bear the risk of exacerbating the medical 'brain drain' and promoting imbalances in distribution of the health workforce [10], [31], with sustainability and ethical repercussions for healthcare global (in)equity.

Reliance on digital 'solutions' may also negatively influence the development of other services - driving out basic health provision. As Rao and Lombardi [32] note, while "telemedicine [projects] have demonstrated positive effects in countries in need, they have not substantially reduced or compensated for a fundamental lack of healthcare". Investments in forms other than face-to-face healthcare provision, may drive healthcare away from holistic care and patient intimacy with the doctor or nurse [33], and leave an unsustainable legacy of fragmentation of care and remoteness of relationships. This is at the very least a very different form of healthcare provision and one that may in time become dislodged from the central place in social and political life that healthcare now enjoys.

Social networks and other web 2.0 technologies show potential as a support structure for patients with chronic conditions and may offer valuable information sources for patients and health professionals [34]. Furthermore, crowd-sourcing is starting to show potential in healthcare as a means to collect and share patient narratives and ratings, used as 'evidence' "for product development, quality improvement, or policy reform" [35]. Though, as the scale of this increases, the 'option' of participating in the social network may be transforming into an 'obligation' - "an obligatory activity" for patients as good citizens [36]. This reminds us that online participation "involves work" [35]- specifically work that is redistributed ("shifted") from healthcare providers and government to patients and carers. This redistribution of work and new areas of responsibility/obligation is not in general financially recognized and suggests that we need to ask if crowd-sourcing is always economically fair?

Online participation also has evident consequences (i.e. externalities) for anonymity and privacy of individuals [37] and presents challenging implications in terms of surveillance. Today the law is still inadequate in most jurisdictions to protect individuals from (possibly incorrect, incomplete, or misleading) information posted online by individuals or companies [38]. Thus the world of social media and online marketing may create new challenges to public health policies, such as undermining stop smoking initiatives [39] or influencing negatively suicide or eating disorders [40].

Data protection laws are also often seen as inadequate for protecting individual's privacy, particularly so when policy is to integrate health data across organizations (within and outside healthcare) and patients are given little choice in the matter. In the United States this concern is a major element of resistance to President Obama's healthcare reforms and one that suggests legitimate ethical concern [41].

Aggregate data collected through the ubiquity of online devices and social media can usefully inform public health debate and support surveillance, providing early 
warning of emergencies, serving clinical research, tracking progress of interventions or informing strategies. However, data aggregation and surveillance evoke easily the image of 'big brother', or the fear that those who are monitoring gain power over people, "including the power to reprimand or punish" [42]. Privacy and associated issues of trust have become central to many health information systems initiatives and are tackled in a number of ways and to various degrees in different jurisdictions. It is unclear today if this concern is or can be adequately addressed by the various professional codes, data protection laws and technical measures available - adequately in the sense of gaining and sustaining public acceptance, minimizing harm, releasing the beneficial potential of digital technologies and retaining choice as to future development. Beyond the many 'solutions' available for aspects of health care practice, there remains a more fundamental set of questions as to the appropriate tests for legitimacy of the use of big data, for example in research, service management, for subpopulation monitoring or for public or private benefits beyond healthcare.

\section{Concluding Remark - Science and Trans-Scientific Questions}

Robert Oppenheimer, discussing the ethical dilemmas of the Manhattan Project says: "when you see something that is technically sweet, you go ahead and do it and you argue what to do about it only after you have had your technical success. That is the way it was with the atomic bomb" (cited in [43]). So too we suspect with health information systems. If it can be built, it will be built, and they will come, not least because there is often a persuasive short-term case to justify the investment and motivate use. But there is or should be more.

Sustainable digital investments in healthcare, a category we introduce here, do need to respond to the immediate needs of citizens for appropriate healthcare provision and the wider concerns of public health, as well as governments' concern for efficiency and value-for-money. But it must do so taking into account distributional effects, externalities, and the technical and societal legacy left to future generations. This is a legacy that will then constrain or promote further innovation.

Taking account of distribution and externalities implies making ethical choices, and hence raise matters of values. The burgeoning investments in ICT and implementation projects in healthcare are matters of politics and ethics, ultimately becoming trans-scientific questions [44] that cannot be answered by science alone. Enid Mumford makes a similar point, quoting Vickers as saying "technology always make ethical demands in what it requires people to expect of each other and therefore of themselves" [45], citing [46] and she goes on to note that "Ethical principles are particularly hard to develop and apply when times are hard, as economic pressures tend to overcome others" [45].

Thus, while policy makers and healthcare organizations keep solving today's problems and looking for 'scientific evidence' (on efficiency and effectiveness) to guide their investments in digital health, they face similar issues to those encountered by NASA on their Challenger missions: 
"Observational data, backed by an intuitive argument, were unacceptable in NASA's science-based, positivistic, rule-bound system. Arguments that could not be supported by data did not meet engineering standards and would not pass the adversarial challenges of the FRR process. [so the hunch on the effect of cold weather on the o-ring was not reported]... Phillip Thompkins ... observed that 'only the easy decisions at Marshall were made by scientific evidence or demonstration. The difficult decisions created a rhetorical problem because the solution could not be demonstrated scientifically"' [47].

Charles Perrow expresses this as a more overtly political concern. Writing about risk in civil nuclear technologies he says: “...where body counting replaces social and cultural values and excludes us from participating in decisions about the risks that a few have decided the many cannot do without. The issue is not risk, but power" [48]

Change cannot stop, indeed probably should not. So accommodations and intelligent reflection and response to these issues (but we would argue not 'solutions'!) will have to be found, pragmatically, while and during the time that digital innovations are introduced into healthcare systems - rather than solving them ex-ante as a priori conditions for technological innovation. The incessant, perhaps even deterministic, pace of technological innovation in any case does not wait for society's considered ethical answers. Indeed, these are old and enduring questions that have been applied to technological innovations of the past, in a variety of fields, and for which, in the past society has had to struggle to find appropriate accommodations. The industrial revolution in Britain and its societal and political consequences are written across at least a century in intense reflection found in literature, natural and political science and the arts.

The new types of ICT innovations we are encountering today - especially the 'free' and participatory models mentioned above - are changing structurally and fundamentally these questions, in their nature and in their possible answers. Even the most straightforward and traditional computer implementations in healthcare require complex judgments [49]. How do we develop the ethical apparatus to deal with them?

Walsham [50] offers some modest ideas as to how we might move in this direction when he asks of the IS community, "Are we making a better world with ICTs?". He goes on suggest that we do not have very convincing answers to this question and thus argues for "a strong ethical agenda" and "...a sharper critical agenda towards existing approaches and power structures...”. Interestingly he makes these comments while contrasting the wider IS field with the firmer ethical underpinning of architects who want to build better buildings, or doctors who want people to live longer and healthier lives.

Thus we suggest here a simple research agenda for sustainability in digital healthcare. This is based on addressing three core ideas:

- Redistribution of risk and responsibility across social actors including the patientcitizen, healthcare professions and the state

- Accounting for externalities in design of systems and in operational practices

- Application of an intergenerational model that can account for constraints placed on possible futures. 


\section{References}

1. Jha, A.K., Doolan, D., Grandt, D., Scott, T., Bates, D.W.: The use of health information technology in seven nations. Int. J. Med. Inform. 77, 848-854 (2008)

2. Suk, J.E., Semenza, J.C.: Future Infectious Disease Threats to Europe. American Journal of Public Health 101, 2068-2079 (2011)

3. Hanvoravongchai, P., Coker, R.: Early reporting of pandemic flu and the challenge of global surveillance: a lesson for Southeast Asia. Southeast Asian J. Trop. Med. Public Health 42, 1093-1099 (2011)

4. NHS: London Health Programmes: Tuberculosis (2012), http: / /www. londonhp.nhs.uk/services/tuberculosis / (last accessed March 17, 2012)

5. Bates, D.W., Gawande, A.A.: Improving Safety with Information Technology. New England Journal of Medicine 348, 2526-2534 (2003),

http: / / www . nejm.org/doi / full/10.1056/NEJMsa020847

(last accessed April 30, 2012)

6. Jackson, G., Krein, S., Alverson, D., Darkins, A., Gunnar, W., Harada, N., Helfrich, C., Houston, T., Klobucar, T., Nazi, K., Poropatich, R., Ralston, J., Bosworth, H.: Defining Core Issues in Utilizing Information Technology to Improve Access: Evaluation and Research Agenda. Journal of General Internal Medicine 26, 623-627 (2011)

7. Joint Services, DLA and USCD: Digital Imaging Systems. In: P2 Opportunity Handbook, Joint Service Pollution Prevention and Sustainability Technical Library, A Website Supported by the Joint Services, the Defense Logistics Agency, and the U.S. Coast Guard, (2008),

http://205.153.241.230/P2_Opportunity_Handbook/12_11.html (last accessed March 26, 2012)

8. Mathieson, S.A.: Videoconference consultants boost emergency stroke care. The Guardian (February 16, 2011),

http: //www. guardian. co.uk/healthcare-

network/2011/feb/16/informatics-hospitals-and-acute-care

(last accessed March 17, 2012)

9. DoH: '3 million lives' initiative. Department of Health, UK,

http: / /www.3millionlives.co.uk/About-Telecare-and-

Telehealth.html (last accessed March 17, 2012)

10. Nuffield Council on Bioethics: Medical profiling and online medicine: the ethics of personalised healthcare in a consumer age. The Nuffield Council on Bioethics (2010), http: / / www nuffieldbioethics . org/personalised-heal thcare-0 (last accessed April 30, 2012)

11. Magee, M., Isakov, A., Paradise, H.T., Sullivan, P.: Mobile phones and short message service texts to collect situational awareness data during simulated public health critical events. Am. J. Disaster Med. 6, 379-385 (2011)

12. Swan, M.: Crowdsourced Health Research Studies: An Important Emerging Complement to Clinical Trials in the Public Health Research Ecosystem. J. Med. Internet. Res. 14, e46 (2012), http: / /www.jmir.org/2012/2/e46/ (last accessed April 30, 2012)

13. Leadbeater, C.: We-Think: Mass innovation, not mass production: The Power of Mass Creativity. Profile Books (2008)

14. Anderson, C.: Free: how today's smartest businesses profit by giving something for nothing. Hyperion, New York (2010)

15. Winner, L.: Do Artifacts Have Politics? In: The Whale and the Reactor: A Search for Limits in an Age of High Technology, pp. 19-39. University of Chicago Press, Chicago (1986) 
16. UN General Assembly: Our Common Future, Report of the World Commission on Environment and Development, World Commission on Environment and Development. In: Published as Annex to General Assembly document A/42/427, Development and International Co-operation: Environment (1987), http: / /www . un-documents . net/ocf02 . htm (last accessed March 17, 2012)

17. Barry, C.: Redistribution. In: Zalta, E.N. (ed.) The Stanford Encyclopedia of Philosophy (2011),

http://plato.stanford.edu/archives/fall2011/entries/redistri bution/ (last accessed March 17, 2012)

18. Vikkels $\varnothing$, S.: Subtle Redistribution of Work, Attention and Risks: Electronic Patient Records and Organisational Consequences. Scandinavian Journal of Information Systems 17, 3-29 (2005)

19. Ash, J., Sittig, D., Campbell, E., Guappone, K., Dykstra, R.: An unintended consequence of CPOE implementation: shifts in power, control, and autonomy. In: AMIA Annu. Symp. Proc., pp. 11-15 (2006)

20. McAlearney, A.S., Chisolm, D.J., Schweikhart, S., Medow, M.A., Kelleher, K.: The story behind the story: Physician skepticism about relying on clinical information technologies to reduce medical errors. Int. J. Med. Inform. 76, 836-842 (2007)

21. Motulsky, A., Sicotte, C., Lamothe, L., Winslade, N., Tamblyn, R.: Electronic prescriptions and disruptions to the jurisdiction of community pharmacists. Social Science \& Medicine 73, 121-128 (2011)

22. Berg, M.: Lessons from a Dinosaur: Mediating IS Research Through an Analysis of the Medical Record. In: Proceedings of the IFIP TC9 WG8.2 International Conference on Home Oriented Informatics and Telematics,: Information, Technology and Society, pp. 487-506. Kluwer, B.V. (2000)

23. Ash, J.S., Sittig, D.F., Poon, E.G., Guappone, K., Campbell, E., Dykstra, R.H.: The Extent and Importance of Unintended Consequences Related to Computerized Provider Order Entry. Journal of the American Medical Informatics Association 14, 415-423 (2007)

24. OECD: Externalities. In: Glossary of statistical terms (2012),

http: / / stats. oecd.org/glossary/detail . asp? ID=3215, (last accessed March 17, 2012)

25. Pigou, A.C.: The Economics of Welfare. Macmillan (1946)

26. Cornes, R., Sandler, T.: The theory of externalities, public goods, and club goods. Cambridge University Press, Cambridge (1996)

27. Samuelson, P.A.: Foundations of economic analysis. Harvard University Press, Cambridge Mass. (1948)

28. NORC: Health Information Exchange Economic Sustainability Panel: Final Report. Prepared for the U.S. Department of Health and Human Services Office of the National Coordinator for Health Information Technology, NORC at the University of Chicago (2009)

29. Aanestad, M.: Information Systems Innovation Research: Between Novel Futures and Durable Presents. In: Chiasson, M., Henfridsson, O., Karsten, H., DeGross, J.I. (eds.) Researching the Future in Information Systems. IFIP AICT, vol. 356, pp. 27-41. Springer, Heidelberg (2011)

30. Mort, M., May, C.R., Williams, T.: Remote Doctors and Absent Patients: Acting at a Distance in Telemedicine? Science, Technology, \& Human Values 28, 274-295 (2003)

31. Dussault, G., Franceschini, M.C.: Not enough there, too many here: understanding geographical imbalances in the distribution of the health workforce. Human Resources for Health 4, Published online (2006), http: / / www .ncbi.nlm.nih.gov/pmc/articles/PMC1481612/

(last accessed April 30, 2012) 
32. Rao, B., Lombardi, A.: Telemedicine: current status in developed and developing countries. J. Drugs Dermatol. 8, 371-375 (2009)

33. Mort, M., Smith, A.: Beyond Information: Intimate Relations in Sociotechnical Practice. Sociology 43, 215-231 (2009)

34. Sarasohn-Kahn, J.: The wisdom of patients: Health care meets online social media. California Healthcare Foundation (2008),

http: / / www. chcf.org/publications / 2008/04/the-wisdom-ofpatients-health-care-meets-online-social-media

(last accessed April 30, 2012)

35. Adams, S.A.: Sourcing the crowd for health services improvement: The reflexive patient and "share-your-experience" websites. Social Science \& Medicine 72, 1069-1076 (2011)

36. Adams, S.A.: "Letting the people speak" or obliging voice through choice? In: Harris, R., Wyatt, S., Wathen, N. (eds.) Configuring Health Consumers. Palgrave Macmillan, Houndmills (2010)

37. Zimmer, M.: The Externalities of Search 2.0: The Emerging Privacy Threats when the Drive for the Perfect Search Engine meets Web 2.0. First Monday 13 (2008),

http: / / firstmonday.org/htbin/cgiwrap/bin/ojs/index.php/fm/ article/viewArticle/2136 (last accessed April 30, 2012)

38. Edwards, L.: Privacy and data protection online: The laws don't work? In: Edwards, E., Waelde, C. (eds.) Law and the Internet, pp. 472-473. Hart Publishing, Oxford and Portland, Oregon (2009)

39. Ribisl, K.M., Jo, C.: Tobacco control is losing ground in the Web 2.0 era: invited commentary. Tobacco Control 21, 145-146 (2012)

40. Luxton, D.D., June, J.D., Fairall, J.M.: Social Media and Suicide: A Public Health Perspective. American Journal of Public Health 102, S195-S200 (2012)

41. Trotter, G.: The Moral Basis for Healthcare Reform in the United States. Cambridge Quarterly of Healthcare Ethics 20, 102-107 (2011)

42. Dobson, J.E.: Big Brother has evolved. Nature (2009), http://www. nature.com/nature/journal/v458/n7241/full/ 458968a. html (last accessed March 23, 2012)

43. Sennett, R.: The craftsman. Yale University Press, New Haven (2008)

44. Weinberg, A.M.: Science and trans-science. Minerva, 209-222 (1972)

45. Mumford, E.: Systems design: ethical tools for ethical change. Macmillan, Basingstoke (1996)

46. Vickers, G.: Making Institutions Work. Associated Business Programmes (1973)

47. Vaughan, D.: The Challenger launch decision: risky technology, culture, and deviance at NASA. University of Chicago Press, Chicago (1996)

48. Perrow, C.: Normal accidents: living with high-risk technologies. Basic Books, New York (1984)

49. Cornford, T., Klecun-Dabrowska, E.: Ethical Perspectives in Evaluation of Telehealth. Cambridge Quarterly of Healthcare Ethics 10, 161-169 (2001)

50. Walsham, G.: Are we making a better world with ICTs? Reflections on a future agenda for the IS field. Journal of Information Technology advance online publication (2012),

http: / / www.palgrave-journals.com/jit/

journal/vaop/ncurrent/abs/jit20124a.html

(last accessed April 30, 2012) 